\title{
A Study of Establishment of the Hearing Procedures in China's University Management
}

\author{
Hui-Hua Zhang \\ School of Law, South China University of Technology, Guangzhou, 510006, China \\ E-mail: hhzhang1@scut.edu.cn
}

\begin{abstract}
Hearing is the embodiment of democratic management. It plays an important role in the university management with its procedure value highlighted. Due to its rigorous procedures, hearing system empowers members of faculty and students to exercise the right of statement, right of defense, and right of petition to voice their stances, thereby furthest curbing the abuse of administrative power, protecting the rights of the parties concerned, reducing the administrative disputes, and improving the construction of harmonious campuses.
\end{abstract}

Keywords-China's university management; procedure value and effect; the establishment of university's hearing procedures

\section{INTRODUCTION}

Democratic management has found itself in hearing, which involves significant procedure value and effect in the administration of universities. In its routine management, the university is compelled to hold hearings on items concerning the vital interests of its staff and students whilst taking its specific conditions into meticulous consideration. The hearing system in university's management is supposed to serve as the theoretical basis for the implementation of university's management. The hearing in the university's management is a safeguard mechanism as proposed to protect the legitimate rights of staff and students, which enables them to practice the right of statement, the right of defense, and the right of petition to express their standpoints, ultimately shielding their legitimate rights from being violated. Thereupon, it is of immense necessity to establish the hearing system in China's university management. ${ }^{[1]}$

\section{FORMAL HEARING PROCEDURE}

The formal hearing procedure is possessed of the features of the judicial litigation procedure. The position of the chairperson of the hearing equals to the esteemed judge, and the petitioner of the hearing and the decision-maker to the plaintiff and the defendant. The formal hearing procedure in the university's management is conducted before the university makes important resolutions related to the identity of staff and students such as dismissal and expulsion. In this process, the quasi-judicial procedures including the submission of evidences by the parties concerned, cross-examination, interrogating, debating, delivering of resolutions from university and the drafting of resolution according to the records of hearing by the institute concerned are phased in.

Since the formal hearing procedure is lower efficient, costly, time-consuming and effort-exerting, it is conditionally applied to dismissing staff and students, appointing the cadres, appraising professional titles, expelling students from school, and refusing to issuing the degree certificate or academic certificate, and so forth. These resolutions are bound to impose influences upon the identity of teachers and students, the students' right of receiving education, and even their expectations and destiny. In this regard, it is of much necessity to hold the hearings and conduct the discussions as elaborately as possible, otherwise the reasonableness, legitimacy, and fairness of the resolutions cannot be safely ensured. Prior to the delivering of resolutions, the parties concerned should be apprised of the right of hearing they are legally granted. Hearings, when required by the teachers or students concerned, should be held by the university.

In the process of hearing, participants should involve the punished to be, student representatives, the teacher representatives, the head of the department, leaders of the university, the witness (es), the instructor (s), the head teacher, leaders of the dean or college responsible for student affairs, and, when necessary, the head of his or her family should be invited. The formal hearing is supposed to be publicly held and other students are permitted to unless it involves the state secrets or private affairs of individuals. The students concerned and their guardians are empowered to request the hearing not being conducted publicly. Whether it is publicly held is determined by the chairperson of the hearing. The formal hearing procedure is characteristic with judicial features. The formal hearing should be implemented in compliance with the following procedures.[2]

\section{A. Notification of the Hearing}

Notification is the beginning of hearing procedures. The institutes that intend to make resolutions are obliged to make the hearing notification letter as stipulated so as to notify the teacher or student concerned as well as the guardian of the right of hearing they have been granted. The hearing notification letter should be sent to the party concerned and the committee of hearing. When necessary, it can be publicly put up. Whereas the notification does not reach to all those who should be notified, the resolution will be out of effect.

\section{B. Request for Hearing}

After receiving the hearing notification letter, the teachers or students concerned and their guardians can 
request for hearing and submit the hearing application form to the committee of hearing within the required time. Whereas the application is not proposed within the required time without justifiable reasons, it is regarded as a waiver of the hearing right. Whereas the teacher or student concerned and their guardians submit the hearing application form within the required time, the committee of hearing is compelled to accept and hold the hearing. [3]

\section{Accepting the Request for Hearing and the Delivering of its Notification}

When the request for hearing is accepted, the organ in charge of holding the hearing is required to notify the party concerned of the time, place, and other related items within the time limit. The Decision Letter of Holding Hearing to which the List of Committee Members are attached should be delivered to the investigators and the hearing applicants within the stipulated time, thus notifying them of the time when the chairperson of the hearing is jointly elected. To be notified prior to the hearing is the legitimate right of the party concerned and complies with the requirement of procedure fairness. The notification is generally written, but sometimes announced, when necessary. Be it written or announced, it must ensure that applicants are notified indeed. As for the contents of the notification, it should include the questions involved, the resolution that the administrative organs drafts, and the rights that applicants have been granted in the process of hearing, except the time and place of the hearing.[4]

\section{The Hearing Meeting}

The hearing is held in a specified place where the party concerned and the investigators, convened by the hearing personnel of the administrative organ, conduct their statement, defense, and interrogation in terms of the facts, reasons, and basis of the administrative penalty decision[5]. In the hearing meeting, the investigators are required to state the facts proving the party concerned has committed the crime, the reasons, and their suggestions. The party concerned is empowered to raise objections against the statement of the investigators, and present the evidences related to testify. After the chairperson of the hearing announces the debate is over, the party concerned is supposed to deliver his or her final statement. So far, the hearing meeting has phased in the statement, defense, and interrogation. Prior to the end of the hearing meeting, the party concerned has the right of delivering his or her final statement. Then the chairperson announces that the hearing is over, and notifies the participants of examining the records of the hearing and sign and seal on them.

Take the hearing procedure of the college's enrollment planning as an example. The hearing procedures of the college's enrollment planning are required to be public, democratic, and effective in the process of designing. The right of information of the participants should be safeguarded and the openness of the hearing procedures upheld, thus making the causes, processes, results, and execution publicly known, eliminating the hearing information asymmetry, and putting an end to the black box operations. Besides, the participant's right of statement and right of defense are legally protected whereby they can voice their opinions and proposals as thoroughly as possible, thereby fully realizing the value of the hearing.

The practical principle and the specifics of the hearing item are supposed to be underscored with respect to determining which hearing procedures should be chosen, the formal or the informal. The formal hearing is conducted through convening a hearing meeting. Generally, after the enrollment plan is put forward, the representatives attending the hearing meeting are responsible for analyzing the proposed enrollment plan, debating with others concerning the specific issues of the plan, and propounding their suggestions. The party responsible for formulating the enrollment plan makes the resolution on the basis of the hearing. The informal hearing is otherwise named summary hearing for its form is flexible and simple, which facilitates the improvement of the efficiency of the hearing. It includes symposium and discussion meeting, and so forth. With the development of the technology of the network, the public opinions on the enrollment plan can be solicited through well-known or official websites [6].

\section{E. The Closing of the Hearing}

After the hearing is closed, the university's administrative organ holds a discussion on the records of hearing, and relates the resolution of the hearing to the party concerned according to different specifics. The chairperson of the hearing is required to make the records of hearing, noting down the reasons of holding the hearing, the briefing of the hearing procedures, and the stance and causes that the party concerned has conveyed. The evidences presented by the investigators, the requester, and the third party, together with the authentication, are supposed to be sealed and signed with the signatures of the chairperson and the clerks before sending them to the party concerned. The decision-making organ delivers its resolution in accordance with the records of hearing. The legal ground as well as the factual basis in line with which the organ has made its resolution are required not to go beyond the bounds of the records.

\section{THE INFORMAL HEARING PROCEDURE}

The informal hearing procedure is conducted through offering the interested party an opportunity of stating their views which serve as references for resolution without holding the hearing characteristic with the judicial trial. It is the procedure which does not require the decision-making organs to refer to the records of the hearing[7]. The informal hearing procedure is flexible and generally applicable to those items that concern little influences on rights and interests. It does not necessitate the judicial trial procedure; neither does it base the resolution on the records of the hearing. By drawing upon the experience that the foreign countries have accumulated on the hearing procedures, it is acknowledged that the informal hearing procedure is generally applicable to the formulation of the regulated documents or policy whereas the formal hearing procedure to punishing the administrative counterpart. 
Although the form of The informal hearing is simple,the key elements that the hearing embraces do not change. That is to say, before clarifying the rights and obligations of the party concerned, the opinions of the party concerned should be solicited so as to make sure that the resolution is legitimate and impartial. Compared with the formal hearing procedure, the informal hearing procedure is very efficient and simple. The formal hearing procedure is time-consuming and effort-exerting as it involves the organization of personnel and the site selection.

Therefore, the items exclusive to the formal hearing can be dealt with by the informal hearing procedure which could remedy the deficiencies such as rigidity and inefficiency of the formal hearing procedure. For example, in the case of the punishment of discipline violation, if the college adopts this simple hearing procedure so as to take heed of the statement and defense of the party concerned before it delivers the resolution, the randomness of the resolution can be probably circumvented and the resolution is likely to be executed as smoothly as possible. Thereupon, universities should attach due importance to the informal hearing procedure, which is of immense significance.

In bid to streamline the hearing procedures, the informal hearing can be applied prior to the formal hearing. As for the hearing procedures in China's university management, the formal hearing procedure has played a dominant role whereas the informal hearing has not been duly highlighted, which should be ascribed to the citizen's inactive participation in the process of the formulation of the legislation and policy related. Contrariwise, the severe administration and bureaucratization in universities have inhibited the initiatives of teachers and students. The informal hearing cannot enjoy its existence in universities. On the other hand, the formal hearing procedure has the noticeable deficiencies of its own in the university's management.

\section{SOME KEY ELEMENTS IN THE HEARING PROCEDURES}

\section{A. The Responsibility Positioning of the Main Body of the Hearing in the University'S Management}

In the formal hearing procedure, the main body includes the organizer of the hearing, the chairperson of the hearing, the investigators, and the interested party. The chairperson of the hearing is appointed by the organizers of the hearing. The chairperson of the hearing is in charge of chairing the hearing. Investigators assume the responsibility of conducting the investigation, and of drafting the decision of punishment. In the hearing procedure of the university's management, the efficiency of the hearing procedure rests with the clear and reasonable responsibility positioning of these four parties.

The responsibilities of the organizers of the hearing: receiving the request of the party concerned or the interested party for the hearing; sending the hearing notification to the party concerned and the interested party within the required time before the hearing; electing or appointing the chairperson of the hearing; delivering the final resolution in accordance with the records of hearing. The organizers of the hearing are obliged to arrange and organize the whole hearing procedure in the neutral and detached pose. Otherwise, the hearing procedure will be deprived of its legitimacy and the acknowledgment of the party concerned, ultimately undermining the initiatives of the participants as well as the party concerned.

The chairperson of the hearing is appointed by the organizers of the hearing. He or she takes the charge of chairing the hearing, interrogating the party concerned and the witness,sequencing the investigations, maintaining the order of the hearing procedure, taking measures if necessary to prevent people from encumbering the hearing, and dealing with the procedure issues of the hearing, and so forth. The chairperson of the hearing equals to the judge in the formal hearing procedure which is quasi-judicial. Thereupon, his or her functions should be positioned in the neutral and detached pose.

In line with the principle of separation of duty, the investigators, the chairperson of the hearing, and the organizers of the hearing are required not to assume the overlapped duties. The chairperson of the hearing should be appointed in line with the principle of the separation of duty, which is an institutional guarantee for the neutrality of the chairperson. The separation of duty is referred to as a means of ensuring that the adjudication is legitimate. Specifically, the hearing institution or the personnel responsible for adjudicating is not permitted to be engaged in the work that has no bearing with adjudication. The chairperson and the institution or personnel responsible for delivering the adjudication cannot assume the duties of prosecutors and investigators, neither can they personally contact with the prosecutor or the investigator. The separation of duty is an important content that the principle of justice involves. To put it simply, by the separation of duty, it means that the party concerned cannot be the judge in charge of the case that concerns him or herself.

The separation of duty can be divided into the complete separation of duty and the internal separation of duty. The complete separation of duty means that the duty of administrative adjudication, the duty of prosecuting, the duty of investigating, and the duty of executing are completely separated and exercised by the independent institutions. The internal separation of duty means that the duty of investigators, the duty of prosecutors, the duty of hearing participants, and the duty of adjudicators are internally separated within an administrative organ. The best interpretation of the separation of duty is the system of administrative law judge implemented in the US. In America, the administrative judge is appointed as the chairperson of the hearing. The administrative judge elected from the personnel who are experienced in administration and qualified for a lawyer engages himself or herself in the work of the hearing.

The administrative judge is independent and not responsible for the chief executive. Each administrative organ is supposed to appoint several hearing examiners according to the requirements of work. The hearing 
examiners are exempted from the trial period and examine the hearing in turns, but cannot assume the duties foreign to the hearing. The hearing examiners cannot be dismissed unless the Civil Officers Affairs Management Committee presents the justifiable reasons and the resolution is examined by the formal hearing. The contents involve the involuntary resignation, early retirement with disablement, demotion, suspension, and other voluntary position transferring. The administrative organ is not empowered to appoint the hearing examiners, but it can select the personnel who are considered eligible by the Civil Officers Affairs Management Committee. The salary of the hearing examiners is regulated by the Civil Officers Affairs Management Committee. Their appointment, salary, and position are not determined by the administrative organ but by the Civil Officers Affairs Management Committee. These regulations are formulated as to ensure that the hearing examiners can undertake their duties independently and spare themselves from the pressure imposed by the administrative organ they are working in [8].

\section{B. The Records of the Hearing}

The records of the hearing are the important references for the administrative decision. The hearing meeting is supposed to make the records of the hearing,literally recording the views and reasons of the speakers. The records of hearing are required to be comprehensive and accurate, which should be signed and sealed after the hearing is closed. In case of mistakes and errors, the hearing meeting can be taped and videoed so as to keep the records as exhaustively as possible. Some grand hearing meetings concerning the administrative decisions can be live broadcast through television and Internet, thereby enlarging the public participation and the disclosure, and affecting the significance of propaganda and instruction. When the hearing is closed, the organ is responsible for organizing the hearing meeting sorts out the summary of the hearing on the basis of the records for the decision-makers to refer to. The summary of the hearing equals to the information abstract of the hearing records [9]. In accordance with the provisions of the fifth Item Article 35 as pronounced in the South Korea's administrative procedure law, after the exhaustive discussion on the records of the hearing and other materials, the administrative organ is supposed to report the results of the hearing whereas they have the justifiable reasons [10]. The records of the hearing serve as the only references on the basis of that the administrative decisions are made. The value of the records is embedded in the legal values of the hearing procedure....... whereas this principle is disobeyed; the right of interrogation is deemed insignificant [11]. Therefore, the records of the hearing should be highlighted as the major references for any resolutions.

\section{REFERENCES}

[1] Huihua Zhang, "Theory of Construction of Chinese Administrative Hearing System in Colleges and Universities", Advances in Economics Business and Management Research AEBMR2015, vol.6, 2015,pp 614.

[2] Weiwei Zhang, "Hearing system research, the university students' management", master degree theses of master of hunan university, 2007.

[3] Huihua Zhang, "On the Hearing and Remedy Approaches of China's University Management", Advances in Economics Business and Management Research, vol6. AEBMR2015, pp622.

[4] Xuan Wan, Rongrong Pan, "The hearing system - college students handle disciplinary procedure guarantee", the education management of colleges and universities, 4th, 2007, pp. 69.

[5] Huiji Yang, Hearing Procedure Theory and Practice, Shanghai People's Publishing House, 1997, pp. 175.

[6] Guangming net<Guangming Daily>, http://news.gmw.cn/2015-03/19/content_15146968_2.htm.

[7] Mianyi Liu, The Scenes Application Research in China, China Legal Publishing House, 2004, pp. 5.

[8] Affairs office of the people's government of Hunan province:<Interpretation of Hunan province administrative procedures>, China Hanshou Net,http://www.hanshou.gov.cn/news/cxfyfg/2008/1029/0810291631 14H9GJ0C14DA948222919D.html）, the last visit date : March 9th, 2011.

[9] Huihua Zhang, "On the Necessity and Feasibility of Hearings in Management System of Chinese Colleges and Universities", International Conference on Management Science and Management Innovation(MSMI2014), vol1.p682.

[10] Wanhua Wang, The Rearch of Administrative Procedural Law Legislation ,China Legal Publishing House, 2000, pp.235.

[11] Xuexian Huang,"The meaning of the hearing record in the administrative decision", Journal of Suzhou university (philosophy),4th, 1999. 